\title{
AGREGAÇÃO E ESTABILIDADE DE AGREGADOS DO SOLO EM SISTEMAS AGROPECUÁRIOS EM MATO GROSSO DO SUL ${ }^{(1)}$
}

\author{
Júlio Cesar Salton $^{(2)}$, João Mielniczuk ${ }^{(3,4)}$, Cimélio Bayer ${ }^{(3,4)}$, \\ Madalena Boeni $^{(5)}$, Paulo Cesar Conceição ${ }^{(5)}$, Amoacy Carvalho \\ Fabrício $^{(2)}$, Manuel Cláudio Motta Macedo ${ }^{(6,4)}$ \& Dirceu Luiz Broch ${ }^{(7)}$
}

\section{RESUMO}

Sistemas de manejo do solo, incluindo lavouras em plantio direto, lavouras (soja) em rotação com pastagens em plantio direto e pastagens permanentes (Brachiaria sp.), foram avaliados quanto à agregação do solo e estabilidade dos agregados. Em três experimentos de longa duração (9 e 11 anos) localizados em Mato Grosso do Sul, o solo foi amostrado nas camadas de 0 a 5,5 a 10 e 10 a 20 cm, para determinação da estabilidade dos agregados em água e a seco. Foram calculados o diâmetro médio ponderado (DMP) e o índice de estabilidade dos agregados (IEA). Em todos os experimentos, nos sistemas com pastagens, seja de forma isolada ou em rotação com lavouras, foi verificado maior volume do solo, constituindo agregados com tamanho superior a $4,76 \mathrm{~mm}$. Os sistemas com pastagens também apresentaram maior DMP e maior IEA em todos os experimentos. O sistema apenas com lavouras apresentou, nos três experimentos, o maior volume de solo com agregados de tamanho entre 0,25 e $2,00 \mathrm{~mm}$. Esses efeitos ocorreram de forma semelhante em todas as profundidades avaliadas. Entre os locais, observou-se o efeito do teor de argila na agregação, sendo maior em Maracaju e menor em Campo Grande. Foi observada estreita relação entre a estabilidade dos agregados e o teor de $\mathrm{C}$ no solo. A formação de macroagregados parece estar relacionada à presença de raízes, que são mais abundantes sob pastagem de gramíneas.

Termos de indexação: plantio direto, pastagem, soja, carbono, matéria orgânica do solo.

\footnotetext{
(1) Parte da Tese de Doutorado do primeiro autor apresentada à Universidade Federal do Rio Grande do Sul - UFRGS. Trabalho com apoio financeiro da Fundação Agrisus e Fundect. Recebido para publicação em novembro de 2006 e aprovado em outubro de 2007.

${ }^{(2)}$ Pesquisador da Embrapa Agropecuária Oeste. BR 163, km 253,6, CEP 79804-970 Dourados (MS). E-mail: salton@cpao.embrapa.br

(3) Professor do Departamento de Solos, Faculdade de Agronomia, Universidade Federal do Rio Grande do Sul - UFRGS. Caixa Postal 776, CEP 90001-970 Porto Alegre (RS). E-mail: mieln@ufrgs.br

(4) Pesquisador do CNPq.

(5) Doutorando do Programa de Pós-Graduação em Ciência do Solo, UFRGS. E-mail: madaboeni@hotmail.com

(6) Pesquisador da Embrapa Gado de Corte, BR 262, km 4, CEP 79002-970 Campo Grande (MS). E-mail: macedo@cnpgc.embrapa.br

(7) Pesquisador da Fundação MS. Estrada da Usina Velha, km 2, CEP 79150-000 Maracaju (MS). E-mail: fms.ms@terra.com.br
} 


\title{
SUMMARY: SOIL AGGREGATION AND AGGREGATE STABILITY UNDER CROP-PASTURE SYSTEMS IN MATO GROSSO DO SUL STATE, BRAZIL
}

\begin{abstract}
Soil management systems, with crops under no-tillage (NT), crops (soybean) in rotation with pastures under NT and permanent pastures (Brachiaria sp.), were evaluated for soil aggregation and aggregate stability. Three long-term experiments (9 and 11 years) in the state of Mato Grosso do Sul were sampled in the layers 0-5, 5-10 and 10-20 cm for determination of the aggregate stability in wet and dry sieving. The mean weight diameter $(M W D)$ and the aggregate stability index (IAS) were calculated. In all experiments, the greatest soil volume was verified in the systems with isolated pastures or in rotation with crops, constituting aggregates of over $4.76 \mathrm{~mm}$. The soil volume was largest in the crop system, in the three experiments, with aggregate sizes between 0.25 and $2.00 \mathrm{~mm}$. These effects ocurred similarly at all studied depths. In the pasture systems, the MWD was largest and IAS highest in all experiments. The clay effect in the aggregation was greatest in Maracaju and lowest in Campo Grande. A close relation between the IAS and soil carbon was observed. The formation of macro-aggregates seems to be related to the presence of roots, which are more abundant under grass pastures.
\end{abstract}

Index terms: carbon, no-tillage, pasture, soil organic matter, soybean.

\section{INTRODUÇÃO}

A crescente expansão da atividade agropecuária na região Centro-Oeste do Brasil tem levado a questionamentos quanto à qualidade dos sistemas de manejo do solo em uso. Um dos principais atributos do solo relacionados a sua qualidade é a formação de macroagregados estáveis, os quais são responsáveis pela estrutura do solo, entre outras propriedades emergentes (Mielniczuk et al., 2003).

As relações entre os agregados do solo e a matéria orgânica do solo (MOS) já foram alvo de muitos estudos, que identificaram, além da fração mineral, a fauna do solo, microrganismos, raízes, agentes inorgânicos e variáveis ambientais como os principais fatores envolvidos na formação e estabilidade de agregados do solo. Em recente revisão, Six et al. (2004) apresentaram uma análise histórica dos modelos propostos sobre os processos de organização e formação de agregados no solo, iniciando com a apresentação de quatro modelos como marcos para entendimento desse processo, desde a proposição de Emerson (1959), que considerou a formação de microagregados em função da ligação entre domínios de argilas orientadas com MOS e partículas de quartzo, sendo a proteção da MOS proporcional à área superficial dos domínios. A seguir, citam a teoria apresentada por Edwards \& Bremner (1967), segundo a qual a formação de microagregados origina-se da reação entre moléculas orgânicas, cátions polivalentes (Fe, Al e Ca) e partículas de argila. Estes autores postularam que a matéria orgânica complexada dentro dos microagregados poderia ser fisicamente protegida e inacessível aos microrganismos. Six et al. (2004) citam, também, o conceito hierárquico de agregação, proposto por Tisdall \& Oades (1982), definindo-o como grande avanço teórico para entendimento da interação entre a MOS e os agregados. Neste modelo, partículas primárias livres e agregados de tamanho de silte são unidos por agentes ligantes persistentes, como matéria orgânica humificada ou complexos com cátions polivalentes, óxidos e aluminossilicatos, formando microagregados $(20$ a $250 \mu \mathrm{m})$. Esses microagregados estáveis são unidos por agentes ligantes temporários (raízes ou hifas de fungos) e transientes (polissacarídeos derivados de microrganismos ou plantas), resultando em macroagregados $(>250 \mu \mathrm{m})$. Dessa forma, os microagregados foram classificados como mais estáveis e menos suscetíveis a práticas agrícolas de manejo do que os macroagregados. Logo em seguida, Oades (1984) acrescenta uma alteração ao modelo hierárquico, na qual propõe que raízes e hifas atuam como núcleos de formação de microagregados e, por serem ligantes temporários, ao se decomporem, formam fragmentos recobertos por mucilagens e incrustados de argilas, dando origem a novos agregados.

O papel das raízes na formação de agregados, especialmente de plantas da família das gramíneas, tem se mostrado muito importante, conforme demonstrado em vários trabalhos, como o de Silva \& Mielniczuk (1997a), que avaliaram a distribuição de tamanho dos agregados estáveis em água em dois solos do Rio Grande do Sul e verificaram maior diâmetro de agregados do solo sob o sistema pangola em comparação a aveia/milho, siratro e solo descoberto. Bronick \& Lal (2005), em trabalho de revisão, apontaram importantes efeitos das raízes, com especial destaque para a rizosfera, na formação e na estabilidade dos agregados. 
Sistemas de preparo de solo associados à rotação de culturas influenciam a estabilidade e o tamanho de agregados, conforme relatam Hernani \& Guimarães (1999). Esses autores verificaram, para condições de Mato Grosso do Sul, ter havido significativa elevação do DMP dos agregados estáveis em água quando o plantio direto foi associado à rotação de culturas, fato que não se repetiu quando o sistema de preparo foi conduzido em ausência da rotação. Quando uma das culturas do sistema é a pastagem, esses efeitos ocorrem de forma acentuada e relativamente rápida, provavelmente devido ao abundante sistema radicular formado pela pastagem logo após sua implantação (Salton et al., 1999).

Como resultado dos fluxos de energia e matéria que ocorrem entre os componentes do sistema agropecuário de produção, há formação de agregados no solo, o que, em escala crescente, representa o grau de organização deste. Em uma fase preliminar, a formação de microagregados (diâmetro inferior a $0,25 \mathrm{~mm}$ ) está relacionada à interação da matéria mineral entre si e com compostos orgânicos. Posteriormente, o crescimento de raízes e hifas de fungos, juntamente com resíduos de vegetais, insetos e outros organismos, estimula a formação de estruturas mais complexas e diversificadas, como macroagregados estáveis, com tamanho superior a $0,25 \mathrm{~mm}$. Essas estruturas correspondem a um nível de organização mais elevado. A ocorrência de fluxos de energia reduzidos resulta em nível de organização baixo, em que a estrutura do solo é simples, com predomínio de microagregados, ao passo que com elevado fluxo de energia e matéria o nível de organização atingido é mais elevado, ocorrendo agregados maiores e formando estruturas grandes e complexas. Assim, solos que apresentem maior agregação podem ser considerados em estado de ordem superior ao de solos semelhantes com menor agregação (Vezzani, 2001).

Com o objetivo de verificar o efeito de sistemas de manejo na agregação do solo, foram avaliados três experimentos de longa duração, implantados em 1993 e 1995, localizados em Mato Grosso do Sul, com lavouras em plantio direto e convencional, pastagens permanentes e sistemas de rotação lavoura-pastagem.

\section{MATERIAL E MÉTODOS}

Três experimentos de longa duração, localizados em Mato Grosso do Sul, foram amostrados em abril de 2004. Em Dourados, o experimento foi implantado em 1995, ocupando área de 28 ha de um Latossolo Vermelho distroférrico típico, caulinítico, da área experimental da Embrapa Agropecuária Oeste. O solo da área experimental possui em média $650 \mathrm{~g} \mathrm{~kg}^{-1} \mathrm{de}$ argila. Antes da implantação do experimento a área era utilizada para cultivo de grãos sob preparo convencional do solo, desde a década de 1970 (Salton, 2005).
Em Maracaju, o experimento foi implantado na área experimental da Fundação MS. O solo é classificado como Latossolo Vermelho distroférrico textura argilosa, com $540 \mathrm{~g} \mathrm{~kg}^{-1}$ de argila. A vegetação natural é do tipo "campo cerrado" e no local há relato de apenas um cultivo de arroz, muitos anos antes de implantação do experimento. Em dezembro de 1992, foi realizada a aplicação de 4 t ha ${ }^{-1}$ de calcário dolomítico, incorporado ao solo com aração e gradagens; também foram aplicados $400 \mathrm{~kg} \mathrm{ha}^{-1}$ de superfosfato simples. Em abril de 1993 foi semeada aveia-preta e, em outubro de 1993, foram implantadas as pastagens e cultura de soja em parcelas com área de $1.500 \mathrm{~m}^{2}$.

Em Campo Grande, o experimento foi implantado na área experimental da Embrapa Gado de Corte, em região representativa das condições de Cerrado típico. Foi estabelecido em 1993, sendo o solo do local classificado como Latossolo Vermelho distrófico, com $360 \mathrm{~g} \mathrm{~kg}^{-1}$ de argila. Antes da instalação do experimento a área era utilizada com pastagem de braquiária, estabelecida em 1973, estando na ocasião em condição de degradação. Antes do início do experimento, em 1993, foram aplicados $80 \mathrm{~kg} \mathrm{ha}^{-1}$ de $_{\mathrm{P}_{2} \mathrm{O}_{5}} \mathrm{e}$ 2,5 $\mathrm{Mg} \mathrm{ha}^{-1}$ de calcário dolomítico em todas as parcelas.

Os sistemas avaliados estão descritos a seguir:

a) L-PC - lavoura em preparo convencional (PC) do solo, utilizando grades de discos (pesada + niveladora), com soja no verão e aveia no inverno em Dourados e apenas soja em Campo Grande.

b) L-PD - lavoura em plantio direto (PD), com a seqüência soja/aveia-preta em Maracaju, nabo/ milho/aveia/soja/trigo/soja em Dourados e milheto/ soja até 2000 e, após isso, sorgo/soja em Campo Grande.

c) $\mathrm{S}_{1} \mathrm{P}_{3}$ - lavoura de soja em plantio direto em rotação com pastagem, no experimento de Campo Grande, constituída de ciclos de um ano de lavoura e três anos de pastagem. A implantação da pastagem (B. brizantha) após a soja é efetuada simultaneamente com milho, que foi adubado conforme as recomendações específicas para a cultura.

d) $\mathrm{S}_{4} \mathrm{P}_{4}$ - lavoura de soja em plantio direto em rotação com pastagem de Panicum maximum cv. Tanzânia, em Campo Grande, com ciclos de quatro anos de lavoura e quatro anos de pastagem, sendo a pastagem de Tanzânia adubada anualmente com $40 \mathrm{~kg} \mathrm{ha}^{-1} \mathrm{de}_{2} \mathrm{O}_{5}$ e $40 \mathrm{~kg} \mathrm{ha}^{-1} \mathrm{de} \mathrm{K}_{2} \mathrm{O}$. No período outono/inverno, entre os cultivos de soja foi semeado milheto ou sorgo, para cobertura do solo e pastejo.

e) $\mathrm{S}_{2} \mathrm{P}_{2}$ - lavoura de soja em rotação com pastagem de $B$. decumbens nos três locais e também com $B$. brizantha em Maracaju, com ciclos de dois anos de lavoura e dois anos de pastagem. A implantação de soja sobre a pastagem e da pastagem após a soja foi em plantio direto. No período outono/inverno, 
entre os dois cultivos de soja, foi semeada aveiapreta para cobertura do solo.

f) PP - pastagem contínua de Brachiaria decumbens nos três locais e também com $B$. brizantha em Maracaju.

g) $\mathrm{PP}+\mathrm{L}$-pastagem permanente com $B$. decumbens implantada em dezembro de 1993, consorciada com leguminosas (Stylosanthes guianensis, $S$. macrocarpa e S. macrocephala e Calopogonium spp.), com adubação de manutenção com $80 \mathrm{~kg} \mathrm{ha}^{-1}$ de $\mathrm{P}_{2} \mathrm{O}_{5}$ e $80 \mathrm{~kg} \mathrm{ha}^{-1}$ de $\mathrm{K}_{2} \mathrm{O}$, a cada dois anos, e submetida a pastejo contínuo, no experimento de Campo Grande.

Em Dourados, as pastagens foram manejadas em pastoreio rotativo, com a lotação ajustada de forma a manter a oferta de forragem constante, em torno de $7 \%$ (7 kg de massa seca de forragem para $100 \mathrm{~kg}$ de peso de animal vivo por dia). Em Campo Grande, o manejo das pastagens foi realizado de forma a manter a matéria seca total em $3 \mathrm{Mg} \mathrm{ha}^{-1}$ ao longo do ano. Em Maracaju houve apenas pastejos esporádicos, com o objetivo de manutenção da pastagem com $40 \mathrm{~cm}$ de altura média.

Em área próxima a cada experimento, foram amostradas áreas não-perturbadas, com vegetação original, para ser utilizada como referência (VN).

Foram coletados monólitos de solo das camadas de 0 a 5,5 a 10 e 10 a $20 \mathrm{~cm}$, nos quais se utilizou o método descrito por Kemper \& Chepil (1965), com alterações propostas por Carpenedo \& Mielniczuk (1990) e Silva \& Mielniczuk (1997b) para obtenção dos agregados e determinação da estabilidade destes. Todo o solo constituinte da amostra foi fracionado, observando-se os pontos de fraqueza, para o volume total da amostra transpassar a malha de $9,51 \mathrm{~mm}$, sendo excluídos dela fragmentos de plantas, outros resíduos, pedras e cascalhos retidos na peneira. A separação dos agregados em classes de tamanho foi feita pela desagregação e peneiramento em meio seco e úmido, com exclusão de partículas individuais simples. Os valores obtidos nos peneiramentos foram usados para cálculo do DMP através da equação: $\mathrm{DMP}=\sum_{i=1}^{n}(x i . w i)$, em que wi $=$ proporção $(\%)$ de cada classe em relação ao total; e xi = diâmetro médio das classes, expresso em mm, e o Índice de Estabilidade dos Agregados (IEA) foi obtido pela equação IEA = $\mathrm{DMP}_{\mathrm{u}} / \mathrm{DMP}_{\mathrm{s}}$, em que o $\mathrm{DMP}_{\mathrm{u}}$ é o DMP obtido pelo peneiramento em água e o $\mathrm{DMP}_{\mathrm{s}}$ é o obtido em peneiramento seco. O C orgânico foi determinado por combustão seca em amostras de solo retiradas das camadas de $0-5,5-10$ e $10-20 \mathrm{~cm}$, e os estoques foram determinados considerando a espessura das camadas, a densidade do solo nestas camadas e o teor de C.

Os dados foram submetidos à análise de variância, aplicando-se o teste F. Foi efetuada a comparação entre as médias pelo teste DMS a $5 \%$ e análise de regressão, sendo utilizados, respectivamente, os softwares Excel e Sigmaplot.

\section{RESULTADOS E DISCUSSÃO}

Os sistemas de manejo, ao influenciarem a intensidade dos fluxos e a dinâmica de matéria e energia para o sistema solo, resultaram em diferentes graus de organização da massa do solo em agregados, como está demonstrado nos quadros 1,2 e 3, que apresentam a distribuição da massa do solo em sete classes de tamanho de agregados estáveis em água. No quadro 1, relativo ao experimento de Dourados, observa-se que os sistemas com presença de pastagem $\left(\mathrm{S}_{2} \mathrm{P}_{2}\right.$ e PP) apresentaram, significativamente, maior quantidade de solo na camada de 0 a $5 \mathrm{~cm}$, constituindo agregados grandes (classe > 4,76 $\mathrm{mm}$ ), em relação aos demais sistemas. Para as classes inferiores a $1 \mathrm{~mm}$ ocorreu o inverso, com os sistemas sem pastagens apresentando maior percentagem, evidenciando que a massa de solo que constitui os agregados grandes $(>4,76 \mathrm{~mm}$ ) foi proveniente das classes de menor tamanho. A maior quantidade de agregados da classe de $4,76 \mathrm{~mm}$ no sistema PP, também na profundidade de 10 a $20 \mathrm{~cm}$, indica a existência de efeito do sistema radicular da pastagem permanente no processo de formação dos macroagregados.

Ao considerar apenas o volume de solo agregado em estruturas menores que $0,25 \mathrm{~mm}$, verifica-se que, em termos gerais, os sistemas de manejo apenas com lavouras, tanto em PC (L-PC) como em PD (L-PD), apresentaram a maior quantidade da massa do solo organizada nesta classe de microagregados, em relação aos outros sistemas. Por outro lado, a massa de solo organizada em macroagregados maiores que $2 \mathrm{~mm}$, nos sistemas com pastagens $\left(\mathrm{S}_{2} \mathrm{P}_{2}\right.$ e $\left.\mathrm{PP}\right)$, atingiu valores superiores a $55 \%$.

No experimento de Maracaju, o solo apresentou a organização da estrutura mais desenvolvida (Quadro 2), em comparação aos demais experimentos, possivelmente em razão do histórico de uso, uma vez que antes da implantação do experimento não havia ocorrido uso agrícola do solo, estando ocupado pela vegetação natural. Além disso, o teor e tipo dos minerais presentes, bem como a maior relação Gb/ $(\mathrm{Gb}+\mathrm{Ct})$, também contribuíram para maior estruturação do solo, em comparação ao solo de Dourados (Salton, 2005). Verificou-se expressiva diferença para a classe de agregados maiores que $4,76 \mathrm{~mm}$, na camada 0 a $5 \mathrm{~cm}$, em que o sistema LPD possuía apenas $15,3 \%$ da massa do solo, enquanto os demais sistemas possuíam entre $38,5 \%\left(\mathrm{~S}_{2} \mathrm{P}_{2} \mathrm{~b}\right)$ e $56,5 \%(\mathrm{PPb})$. Na camada inferior $(5-10 \mathrm{~cm})$, o sistema L-PD apresentou praticamente o dobro de massa do solo na classe $>4,76 \mathrm{~mm}$, em relação à camada de 0 $5 \mathrm{~cm}$. Contudo, o sistema L-PD continuou sendo significativamente diferente em relação aos demais. Na camada mais profunda, para a classe de agregados grandes $(>4,76 \mathrm{~mm})$, também foram verificadas diferenças significativas entre os sistemas com pastagem permanente ( $\mathrm{PPd}$ e $\mathrm{PPb})$ e os sistemas com rotação soja/pastagem, que, no entanto, não diferiram 
Quadro 1. Distribuição relativa da massa de um Latossolo Vermelho distroférrico típico de Dourados, MS, quanto ao tamanho dos agregados estáveis em água, nas camadas de 0 a 5,5 a 10 e 10 a 20 cm, submetido a sistemas de manejo durante nove anos

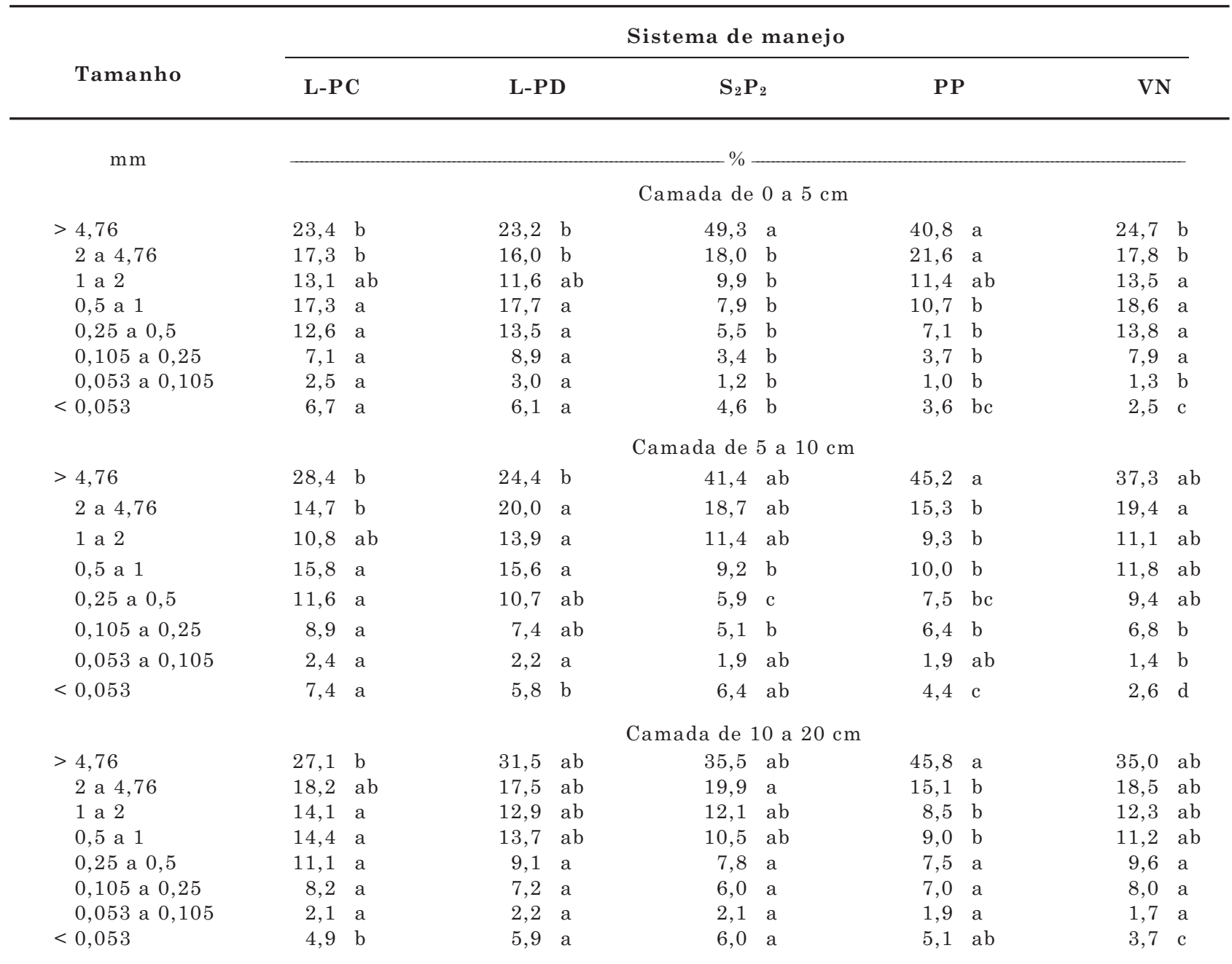

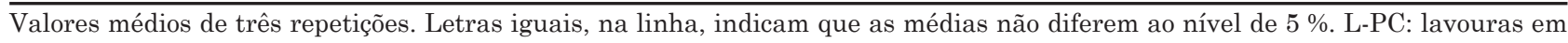
sistema convencional; L-PD: lavouras em plantio direto; $\mathrm{S}_{2} \mathrm{P}_{2}$ : rotação soja por dois anos/pastagem (B. decumbens) por dois anos em plantio direto; PP: pastagem permanente de $B$. decumbens; VN: vegetação natural.

do sistema apenas com lavoura. De modo geral, independentemente da profundidade, neste experimento foram observados maiores percentuais de agregados grandes nos sistemas com pastagem permanente e menores para o sistema L-PD, ficando os sistemas com a rotação lavoura-pastagem em posição intermediária. A atividade do sistema radicular das gramíneas, associado à ausência de revolvimento do solo, contribui efetivamente para formação de macroagregados estáveis, conforme os dados apresentados por Pinheiro et al. (2004), em que um Latossolo do Rio de Janeiro apresentou DMP de 4,2 $\mathrm{mm}$ quando sob gramínea, $3 \mathrm{~mm}$ sob plantio direto e $2 \mathrm{~mm}$ para o sistema convencional.

No experimento de Campo Grande, o solo apresentou textura leve, com $360 \mathrm{~g} \mathrm{~kg}^{-1}$ de argila, o que implica menor nível de organização em comparação a solos mais argilosos, uma vez que as associações entre elementos minerais são menos intensas. Contudo, nessa situação o efeito dos sistemas de manejo foi mais pronunciado do que nos outros experimentos (Dourados e Maracaju). A quantidade de solo com agregados de tamanho superior a $4,76 \mathrm{~mm}$, na camada de 0 a $5 \mathrm{~cm}$, variou de $40,9 \%$ para o sistema $\mathrm{S}_{1} \mathrm{P}_{3}$ a apenas 4,0\% para o sistema L-PC (Quadro 3). Foi muito evidente o efeito da pastagem em aumentar a quantidade de massa de solo organizada em agregados grandes, inclusive na classe de 2 a $4,76 \mathrm{~mm}$, que correspondeu a 20,6\% no sistema PP, em contraste com o valor de 7,6 \% n \% para o sistema L-PC.

$\mathrm{O}$ solo constituinte dos agregados grandes originouse dos agregados menores, pois, enquanto os sistemas 
Quadro 2. Distribuição relativa da massa de um Latossolo Vermelho de Maracaju, MS, quanto ao tamanho dos agregados estáveis em água, nas camadas de 0 a 5, 5 a 10 e 10 a $20 \mathrm{~cm}$, submetido a sistemas de manejo durante 11 anos

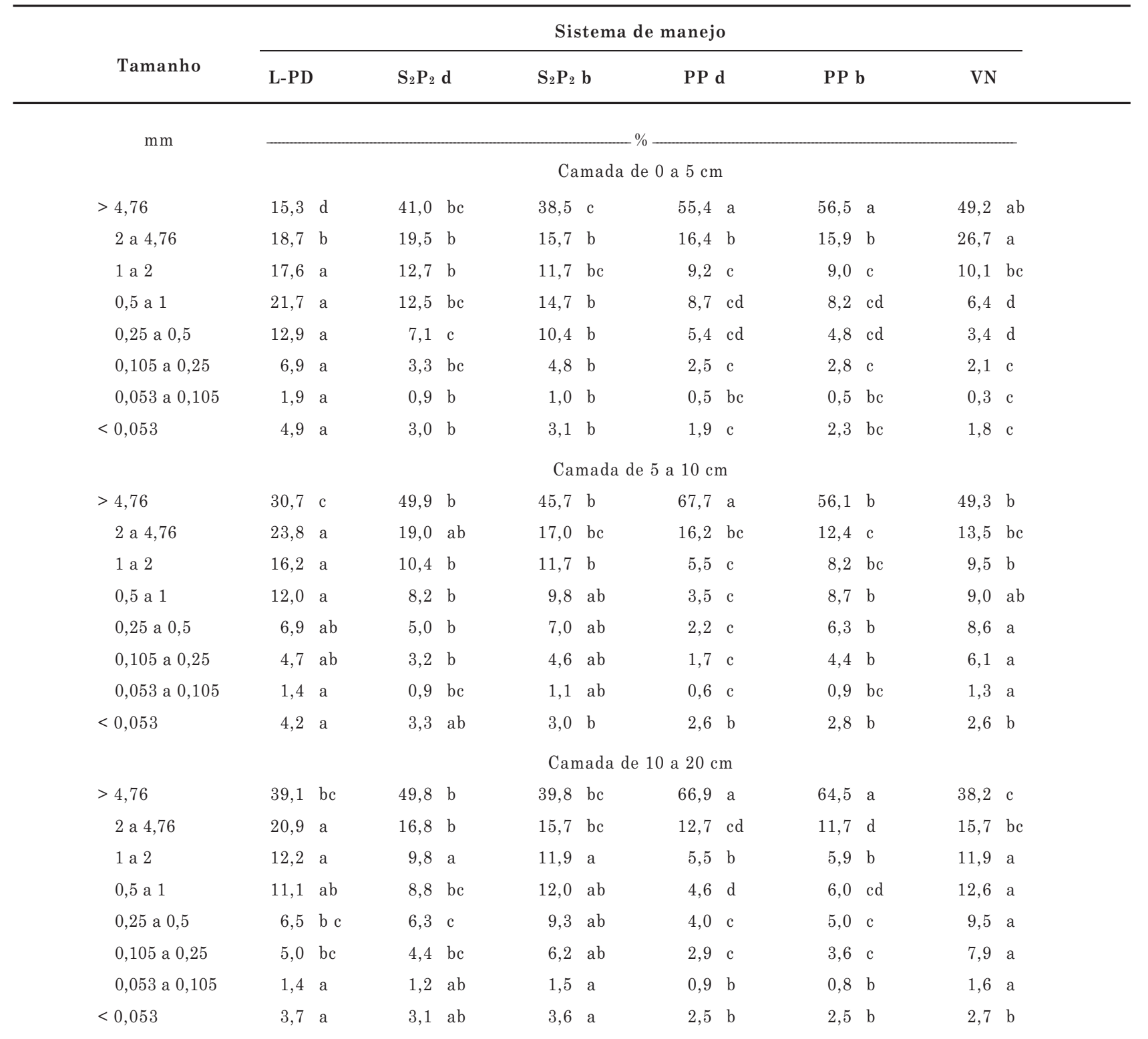

Valores médios de três repetições. Letras iguais, na linha, indicam que as médias não diferem ao nível de 5 \%. L-PD: lavouras em plantio direto; $\mathrm{S}_{2} \mathrm{P}_{2} \mathrm{~d}$ : rotação soja por dois anos - pastagem (B. decumbens) por dois anos; $\mathrm{S}_{2} \mathrm{P}_{2} \mathrm{~b}$ : rotação soja por dois anos pastagem (B. brizantha) por dois anos; PPd: pastagem permanente (B. decumbens); PPb: pastagem permanente (B. brizantha); VN: vegetação natural.

apenas com lavouras apresentaram 65,9 e 47,7\% da massa total do solo em agregados menores que $0,5 \mathrm{~mm}$, respectivamente para L-PC e L-PD, os sistemas com pastagem possuem apenas $25,1 \%(\mathrm{PP})$ e $19,9 \%(\mathrm{PP}+\mathrm{L})$ nesta classe de tamanho, na camada de 0 a $5 \mathrm{~cm}$.

Para as camadas mais profundas, as diferenças verificadas são menores, porém mantêm a mesma proporcionalidade entre os vários sistemas.

As informações relacionadas à distribuição dos agregados do solo podem ser sintetizadas por meio do cálculo do DMP, que permite comparar diversos sistemas de manejo quanto à organização da estrutura do solo. Na figura 1 são apresentados os valores de DMP para vários sistemas de manejo, em três profundidades e locais. Observou-se que os agregados estáveis de maior diâmetro foram encontrados, de forma constante em todo o perfil, nos sistemas com pastagem em rotação com soja e na pastagem permanente. Os menores valores foram verificados nos sistemas com agricultura contínua. Ficou evidente a contribuição da pastagem em aumentar o tamanho 
Quadro 3. Distribuição relativa da massa de um Latossolo Vermelho de Campo Grande, MS, quanto ao tamanho dos agregados estáveis em água, nas camadas de 0 a 5,5 a 10 e 10 a 20 cm, submetido a sistemas de manejo durante 11 anos

\begin{tabular}{|c|c|c|c|c|c|c|c|}
\hline \multirow{2}{*}{ Tamanho } & \multicolumn{7}{|c|}{ Sistema de manejo } \\
\hline & L-PC & L-PD & $\mathbf{S}_{1} \mathbf{P}_{3}$ & $\mathbf{S}_{4} \mathbf{P}_{4}$ & $\mathbf{P P}$ & $\mathbf{P P}+\mathbf{L}$ & $\mathbf{V N}$ \\
\hline \multicolumn{8}{|l|}{$\mathrm{mm}$} \\
\hline & \multicolumn{7}{|c|}{ Camada de 0 a $5 \mathrm{~cm}$} \\
\hline$>4,76$ & $4,0 \mathrm{f}$ & $13,3 \mathrm{e}$ & 40,9 a & $26,6 \mathrm{~cd}$ & $31,6 \mathrm{bc}$ & $38,4 \mathrm{ab}$ & $21,8 \mathrm{de}$ \\
\hline 2 a 4,76 & $7,6 \mathrm{c}$ & $11,5 \mathrm{~b}$ & $11,5 \mathrm{~b}$ & $11,8 \mathrm{~b}$ & 20,6 a & $17,0 \mathrm{a}$ & $17,9 \mathrm{a}$ \\
\hline 1 a 2 & $9,0 \mathrm{bc}$ & $9,2 \mathrm{bc}$ & $8,0 \mathrm{c}$ & $8,3 \mathrm{bc}$ & $11,2 \mathrm{ab}$ & $13,5 \mathrm{a}$ & $14,2 \mathrm{a}$ \\
\hline 0,5 a 1 & $13,5 \mathrm{~b}$ & $18,3 \mathrm{a}$ & $10,9 \mathrm{~b}$ & $13,3 \mathrm{~b}$ & $11,6 \mathrm{~b}$ & $11,2 \mathrm{~b}$ & $19,8 \mathrm{a}$ \\
\hline 0,25 a 0,5 & $34,3 \mathrm{a}$ & $28,5 \mathrm{~b}$ & $14,0 \mathrm{~cd}$ & $19,1 \mathrm{c}$ & $14,0 \mathrm{~cd}$ & $11,3 \mathrm{~d}$ & $17,3 \mathrm{c}$ \\
\hline 0,105 a 0,25 & $19,1 \mathrm{a}$ & $10,7 \mathrm{~b}$ & $8,4 \mathrm{bc}$ & $11,9 \mathrm{~b}$ & $6,2 \mathrm{c}$ & $4,9 \mathrm{c}$ & $6,4 \mathrm{c}$ \\
\hline 0,053 a 0,105 & $3,5 \mathrm{a}$ & $2,7 \mathrm{~b}$ & $1,6 \mathrm{c}$ & $2,8 \mathrm{~b}$ & $1,1 \mathrm{~cd}$ & $0,9 \mathrm{~d}$ & $0,8 \mathrm{~d}$ \\
\hline \multirow[t]{2}{*}{$<0,053$} & 8,9 a & $5,7 \mathrm{bc}$ & $4,6 \mathrm{~cd}$ & $6,1 \mathrm{~b}$ & $3,7 \mathrm{de}$ & 2,8 ef & $1,8 \mathrm{f}$ \\
\hline & \multicolumn{7}{|c|}{ Camada de 5 a $10 \mathrm{~cm}$} \\
\hline$>4,76$ & $3,7 \mathrm{~d}$ & $21,9 \mathrm{bc}$ & 35,5 a & $25,8 \mathrm{~b}$ & 38,4 a & 33,6 a & $18,0 \mathrm{c}$ \\
\hline 2 a 4,76 & $9,2 \mathrm{~d}$ & $13,3 \mathrm{bc}$ & $12,9 \mathrm{c}$ & $13,4 \mathrm{bc}$ & 23,9 a & $16,7 \mathrm{~b}$ & $20,5 \mathrm{a}$ \\
\hline 1 a 2 & $10,6 \mathrm{bc}$ & $10,1 \mathrm{c}$ & $8,9 \mathrm{c}$ & $10,1 \mathrm{bc}$ & $9,9 \mathrm{c}$ & $13,1 \mathrm{ab}$ & $14,9 \mathrm{a}$ \\
\hline 0,5 a 1 & $16,5 \mathrm{ab}$ & $13,3 \mathrm{~b}$ & $13,6 \mathrm{~b}$ & $13,1 \mathrm{bc}$ & $8,9 \mathrm{c}$ & $13,1 \mathrm{bc}$ & $20,2 \mathrm{a}$ \\
\hline 0,25 a 0,5 & 33,4 a & $24,1 \mathrm{~b}$ & $14,9 \mathrm{de}$ & $19,9 \mathrm{c}$ & $11,1 \mathrm{f}$ & 13,2 ef & $16,2 \mathrm{~d}$ \\
\hline 0,105 a 0,25 & $15,2 \mathrm{a}$ & $10,4 \mathrm{bc}$ & $8,4 \mathrm{c}$ & $10,5 \mathrm{~b}$ & $4,7 \mathrm{~d}$ & $7,0 \mathrm{~cd}$ & $7,6 \mathrm{c}$ \\
\hline 0,053 a 0,105 & $3,2 \mathrm{a}$ & $2,2 \mathrm{bc}$ & $1,9 \mathrm{c}$ & $2,4 \mathrm{~b}$ & $0,8 \mathrm{~d}$ & $0,9 \mathrm{~d}$ & $0,8 \mathrm{~d}$ \\
\hline \multirow[t]{2}{*}{$<0,053$} & 8,1 a & $4,7 \mathrm{~b}$ & $4,0 \mathrm{~b}$ & $4,8 \mathrm{~b}$ & $2,4 \mathrm{c}$ & $2,6 \mathrm{c}$ & $1,7 \mathrm{c}$ \\
\hline & \multicolumn{7}{|c|}{ Camada de 10 a $20 \mathrm{~cm}$} \\
\hline$>4,76$ & $7,3 \mathrm{e}$ & $16,8 \mathrm{~cd}$ & $30,9 \mathrm{ab}$ & $19,4 \mathrm{~cd}$ & 36,5 a & $24,3 \mathrm{bc}$ & $15,8 \mathrm{~d}$ \\
\hline 2 a 4,76 & $11,6 \mathrm{c}$ & $15,5 \mathrm{~b}$ & $15,0 \mathrm{bc}$ & $14,3 \mathrm{bc}$ & 21,9 a & $14,2 \mathrm{bc}$ & 19,2 a \\
\hline 1 a 2 & $10,2 \mathrm{bcd}$ & $11,4 \mathrm{bc}$ & $9,2 \mathrm{~cd}$ & $11,1 \mathrm{bcd}$ & $8,6 \mathrm{~d}$ & $11,9 \mathrm{~b}$ & 18,9 a \\
\hline 0,5 a 1 & $17,4 \mathrm{~b}$ & $14,9 \mathrm{bcd}$ & $13,3 \mathrm{de}$ & $14,6 \mathrm{~cd}$ & $11,1 \mathrm{e}$ & $16,3 \mathrm{bc}$ & $21,1 \mathrm{a}$ \\
\hline 0,25 a 0,5 & 32,1 a & $24,6 \mathrm{~b}$ & $15,6 \mathrm{c}$ & $21,7 \mathrm{~b}$ & $13,3 \mathrm{c}$ & $21,2 \mathrm{~b}$ & $15,0 \mathrm{c}$ \\
\hline 0,105 a 0,25 & $12,5 \mathrm{a}$ & $10,5 \mathrm{ab}$ & 10,6 a & 11,8 a & $5,5 \mathrm{c}$ & $7,9 \mathrm{bc}$ & $7,4 \mathrm{c}$ \\
\hline 0,053 a 0,105 & $2,6 \mathrm{a}$ & $2,0 \mathrm{~b}$ & $1,9 \mathrm{bc}$ & $2,2 \mathrm{ab}$ & $0,8 \mathrm{e}$ & $1,3 \mathrm{~cd}$ & $0,9 \mathrm{de}$ \\
\hline$<0,053$ & $6,2 \mathrm{a}$ & $4,2 \mathrm{bc}$ & $3,5 \mathrm{~cd}$ & $4,9 \mathrm{~b}$ & $2,3 \mathrm{ef}$ & $2,8 \mathrm{de}$ & $1,7 \mathrm{f}$ \\
\hline
\end{tabular}

Valores médios de três repetições. Letras iguais, na linha, indicam que as médias não diferem ao nível de 5 \%. L-PC: lavouras em plantio convencional; L-PD: lavouras em plantio direto; $\mathrm{S}_{1} \mathrm{P}_{3}$ : rotação soja por um ano - pastagem (B. brizantha) por três anos; $\mathrm{S}_{4} \mathrm{P}_{4}$ : rotação soja por quatro anos - pastagem ( $P$. maximum) por quatro anos; PP: pastagem permanente (B. decumbens); PP + L: pastagem permanente (B. decumbens) consorciada com leguminosas; VN: vegetação natural.

médio dos agregados estáveis, variando, na camada de 0 a $5 \mathrm{~cm}$, de 0,95 a $4,79 \mathrm{~mm}$, respectivamente para o sistema L-PC em Campo Grande e PP em Maracaju. Em termos gerais, o experimento de Maracaju apresentou maior DMP, possivelmente devido às características do solo e à forma de utilização deste, que era mantido com vegetação natural antes de implantação do experimento em 1994. Em todos os experimentos foi observada a mesma seqüência, com maior DMP para os sistemas com pastagens. Os menores valores foram observados nos sistemas apenas com lavouras; sob o sistema convencional, o DMP foi inferior ao plantio direto, conforme observado em experimentos de longa duração, em outros locais e cultivos, como os avaliados por Wright \& Frank (2005) nos Estados Unidos, com as culturas de sorgo, trigo e soja, e por Albuquerque et al. (2005) em Latossolo Bruno argiloso de Guarapuava, com sistemas de culturas envolvendo soja e milho no verão e trigo, nabo, ervilhaca e cevada no inverno. O efeito das pastagens na agregação do solo é atribuído ao crescimento e à atividade do sistema radicular das gramíneas (Tisdall \& Oades, 1982; Gijsman, 1996; Silva \& Mielniczuk, 1997a; Silva et al., 1998; Liu et al., 2005).

$\mathrm{O}$ aporte de $\mathrm{C}$ ao solo, via raízes especialmente, é fundamental para existência de macroagregados, o que é evidenciado pelos sistemas com pastagem permanente, que apresentaram DMP significativamente maior que os sistemas com pastagem em rotação com soja, e estes, maior em relação ao sistema apenas com 
lavouras (Figura 1). A ação mecânica decorrente do crescimento e funcionamento das raízes, microrganismos e da fauna do solo, que são estimuladas com a presença de pastagens, proporciona o agrupamento dos microagregados, resultando na formação de macroagregados (Haynes \& Beare, 1996). Na figura 1 também

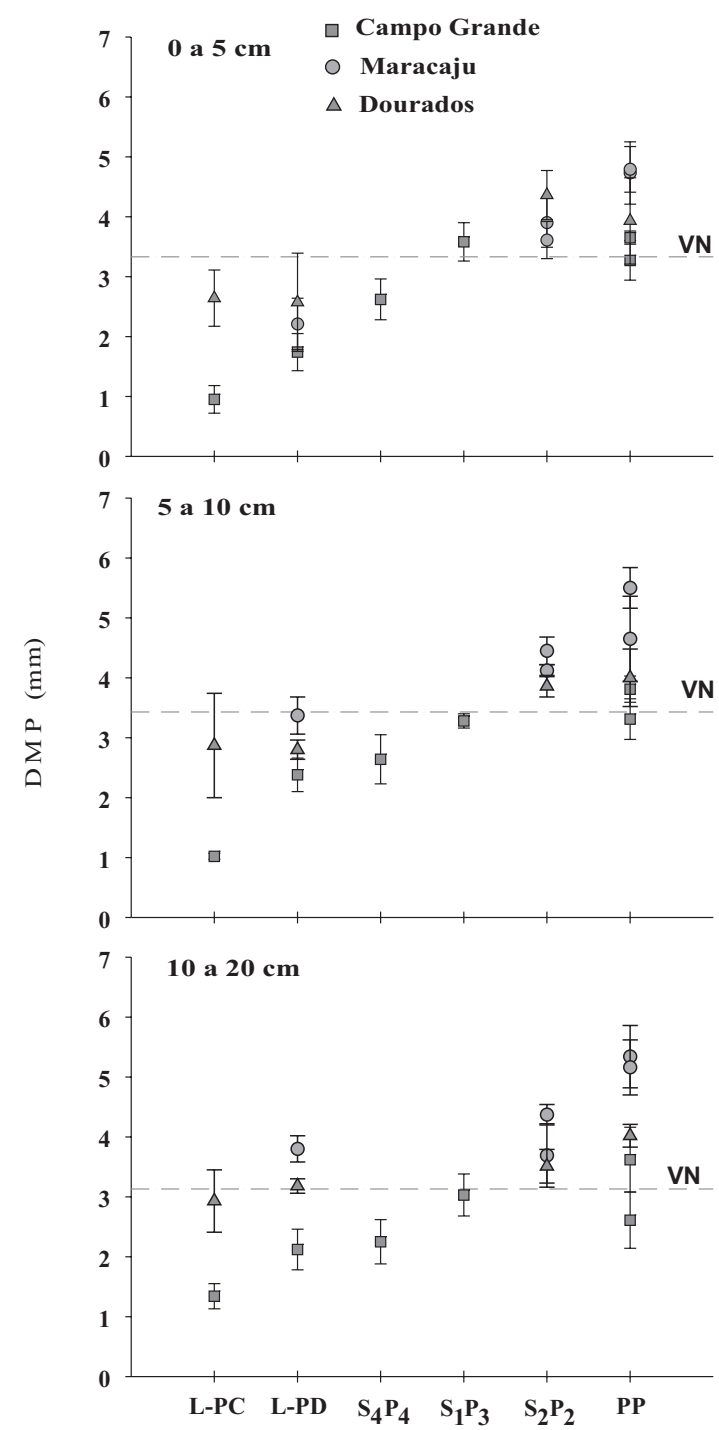

Figura 1. Variações do diâmetro médio ponderado (DMP) dos agregados estáveis em função de sistemas de manejo com lavouras e da intensidade de presença de pastagens, em três camadas do solo e experimentos de longa duração em Mato Grosso do Sul. D: Dourados; M: Maracaju; C: Campo Grande; L-PC: lavouras em plantio convencional; L-PD: lavouras em plantio direto; $S_{4} P_{4}$ : rotação soja por 4 anos pastagem ( $P$. maximum) por 4 anos; $S_{1} P_{3}$ : rotação soja por um ano - pastagem (B. brizantha) por 3 anos; $S_{2} P_{2}$ : rotação soja por 2 anos - pastagem (B. decumbens) por 2 anos; PP: pastagem permanente (B. decumbens); VN: vegetação natural (média dos três locais). é possível observar o efeito dos sistemas de manejo, com presença de pastagens, na variação do DMP em profundidade, sendo reduzido à medida que aumenta a profundidade da camada avaliada.

Macroagregados formados por processos físicos, por meio de operações mecânicas de máquinas e equipamentos ou pelo pisoteio de animais, podem não ser estáveis. Contudo, o que confere maior estabilidade aos agregados são agentes cimentantes ligados a aspectos biológicos, como a atividade microbiana, liberação de exsudatos por raízes, crescimento e funcionamento das raízes, crescimento e morte dos tecidos, entre outros.

O IEA foi calculado para os sistemas de manejo nos três experimentos, apresentando amplitude de valores entre o máximo $(1,0)$ para a pastagem permanente em Maracaju e 0,65 para o sistema com lavoura (L-PC) em Dourados (Figura 2). Isso significa que, para o manejo L-PC em Dourados, apenas $65 \%$ dos agregados obtidos pelo peneiramento seco se mantiveram íntegros ao serem peneirados em água. Nos três experimentos, os sistemas com pastagem permanente apresentaram maior IEA; o sistema de lavouras, o menor; e a rotação lavoura-pastagem, valores intermediários. Apenas no experimento de Dourados o sistema de referência (VN) não foi superado pelo $\mathrm{PP}$. Na análise geral, observa-se que o experimento de Dourados apresentou os valores

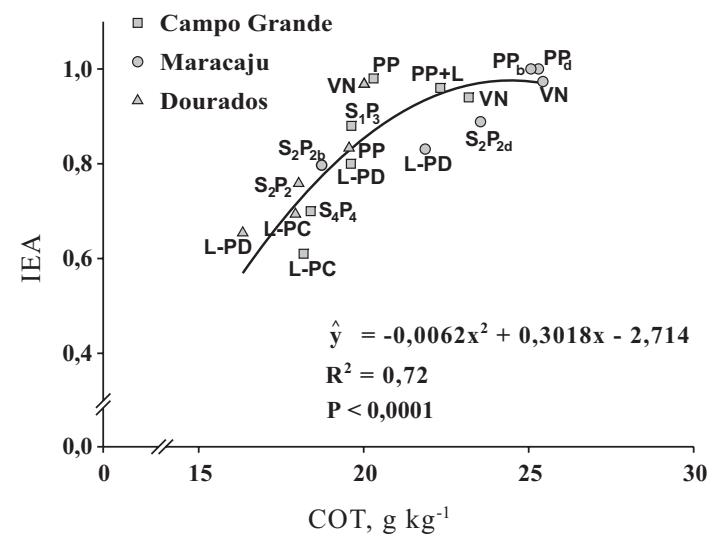

Figura 2. Relação entre carbono orgânico total (COT) do solo e o índice de estabilidade dos agregados (IEA), na camada de 0 a $20 \mathrm{~cm}$ de Latossolos sob sistemas de manejo em experimentos de longa duração em Mato Grosso do Sul. L-PC: lavouras em plantio convencional; L-PD: lavouras em plantio direto; $S_{4} P_{4}$ : rotação soja por 4 anos pastagem ( $P$. maximum) por 4 anos; $S_{1} P_{3}$ : rotação soja por um ano - pastagem $(B$. brizantha) por 3 anos; $S_{2} P_{2 d}$ : rotação soja por 2 anos - pastagem (B. decumbens) por 2 anos; $\mathrm{S}_{2} \mathrm{P}_{2 b}$ : rotação soja por 2 anos - pastagem (B. brizantha) por 2 anos; $P P_{d}$ : pastagem permanente (B. decumbens); $\mathrm{PPb}$ : pastagem permanente $(B$. brizantha); VN: vegetação natural. 
inferiores, o que pode estar associado ao período anterior à instalação do experimento, no qual a área foi submetida ao preparo convencional do solo, com intensa utilização de gradagens, por cerca de 20 anos.

Sistemas de manejo que proporcionem agregados mais resistentes são desejáveis, pois manterão a estrutura do solo sem grandes alterações quando submetidos a forças externas, como pisoteio de animais e operações mecanizadas, além de maior resistência a perdas por erosão. Ao relacionar o IEA com a concentração de C orgânico total (COT) no solo, verificou-se relação significativa $(\mathrm{P}<0,0001)$ entre essas variáveis (Figura 2); o melhor ajuste dos dados foi do tipo curvilinear, atingindo valores de IEA próximos a 0,9 quando a concentração de COT superou $20 \mathrm{~g} \mathrm{~kg}^{-1}$ de C no solo. Esses resultados estão de acordo com as informações existentes quanto ao fato de a estabilidade dos agregados estar associada ao aporte de $\mathrm{C}$ via produção de matéria seca das culturas (Haynes \& Beare, 1997) e à presença de $\mathrm{C}$ no solo, que é importante constituinte dos agentes ligantes (Blair et al., 2005), bem como à maior atividade biológica no solo (Bronick \& Lal, 2005).

Silva et al. (1998) avaliaram a estabilidade de agregados de um Latossolo Vermelho-Escuro argiloso do Cerrado e observaram maiores valores para o cultivo de milho após $B$. ruziziensis em comparação a milho após outras espécies de adubos verdes, apesar de o solo ser submetido ao preparo convencional. A maior estabilidade dos agregados sob pastagem se deve à ação das raízes (Paladini \& Mielniczuk, 1991), à liberação de exsudatos por hifas de micorrizas associadas (Tisdall \& Oades,1982), além da presença de polissacarídeos, que se relaciona fortemente com a maior estabilidade dos agregados (Reid \& Goss, 1981; Liu et al., 2005). Outro fator a ser considerado para justificar a maior estabilidade dos agregados relacionase à ação da fauna do solo (Stefan \& Zhang, 1997); no experimento de Dourados, nas áreas com pastagem permanente e em rotação com soja, foi observada maior presença da fauna do solo, sobretudo de oligoquetas (Silva et al., 2006).

Como os processos de estabilização dos microagregados são relativamente permanentes, as alterações causadas pela adição de $\mathrm{C}$ ao solo ocorrem predominantemente em macroagregados (Tisdall \& Oades, 1982). Dessa forma, os sistemas de manejo afetam a estabilidade dos agregados com tamanho $>250 \mu \mathrm{m}$, que, nestes experimentos, constituem cerca de $80 \%$ da massa de solo. Agregados estáveis são importantes para proporcionar boa estrutura do solo, provendo o interior deste com espaços porosos para desenvolvimento das raízes, da fauna do solo e circulação de ar e água.

Além de aspectos como manejo e clima, a agregação do solo também está associada à sua textura (Bronick $\&$ Lal, 2005), o que também foi verificado neste trabalho, com os maiores valores de DMP no experimento de Maracaju e os menores no de Campo Grande, cujos solos contêm, respectivamente, 540 e $360 \mathrm{~g} \mathrm{~kg}^{-1}$ de argila. Além das interações entre os minerais, a interação destes com a matéria orgânica, constituindo complexos organominerais, afeta intensamente o tamanho dos agregados estáveis em água (Christensen, 2001). A figura 3 apresenta a relação entre o estoque de COT e o DMP para os três locais estudados. Verifica-se considerável acréscimo no tamanho dos agregados estáveis à medida que aumenta o estoque de COT, o que, para os três experimentos, corresponde à alteração do sistema de manejo, passando à utilização apenas de lavouras para rotação lavourapastagem e, por fim, de pastagem permanente.

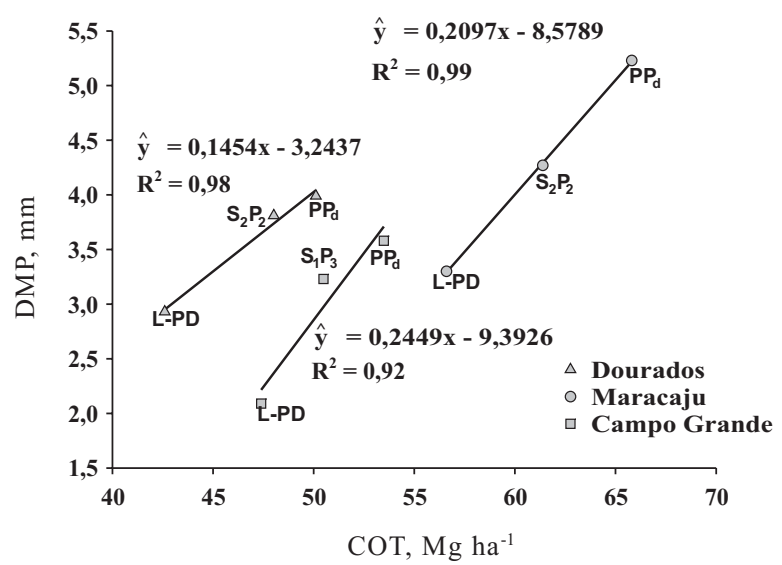

Figura 3. Relação entre o estoque de carbono orgânico do solo (COT) e o diâmetro médio ponderado de agregados estáveis em água (DMP), na camada de 0 a $20 \mathrm{~cm}$ de Latossolos sob sistemas de manejo em experimentos de longa duração em Dourados, Maracaju e Campo Grande, MS. L-PD: lavouras em plantio direto; $\mathrm{S}_{1} \mathbf{P}_{3}$ : rotação soja por um ano - pastagem (B. brizantha) por 3 anos; $S_{2} P_{2}$ : rotação soja por 2 anos - pastagem (B. decumbens) por 2 anos; $P P_{d}$ : pastagem permanente (B. decumbens).

\section{CONCLUSÕES}

1. Sistemas de manejo do solo com pastagem permanente ou em rotação com lavoura em plantio direto favorecem a formação de agregados estáveis de maior tamanho, em relação a sistemas apenas com lavouras ou com lavouras em rotação com pastagens em ciclos maiores que três anos.

2. A manutenção do diâmetro médio ponderado dos agregados estáveis (DMP), com valores semelhantes ou superiores aos verificados na condição de vegetação natural, somente foi obtida com a rotação lavourapastagem em ciclos de dois anos ou com pastagem permanente.

3. A estabilidade dos macroagregados está relacionada ao teor de C orgânico no solo. 


\section{AGRADECIMENTOS}

À Fundação Agrisus e Fundect, pelo apoio financeiro.

\section{LITERATURA CITADA}

ALBUQERQUE, J.A.; MAFRA, A.L.; FONTOURA, S.M.V.; BAYER, C. \& PASSOS, J.F.M. Avaliação de sistemas de preparo e calagem de um Latossolo Bruno Alumínico. R. Bras. Ci. Solo, 29:963-975, 2005.

BLAIR, N.; FAULKNER, R.D.; TILL, A.R. \& POULTON, P.R. Long-term management impacts on soil C, N and physical fertility I. Broadbalk experiment. Soil Till. Res., 2005. (In Press)

BRONICK, C.J. \& LAL, R. Soil structure and management: A review. Geoderma, 124:3-22, 2005.

CARPENEDO, V. \& MIELNICZUK, J. Estado de agregação e qualidade de agregados de Latossolos roxos, submetidos a diferentes sistemas de manejo. R. Bras. Ci. Solo, 14:99 $105,1990$.

CHRISTENSEN, B.T. Physical fractionation of soil and structural and functional complexity in organic matter turnover. Eur. J. Soil Sci., 52:345-353, 2001.

EDWARDS, A.P. \& BREMNER, J.M. Dispersion of soil particles by sonic vibration. Eur. J. Soil Sci., 18:47-63, 1967.

EMERSON, W.W. The structure of soil crumbs. Eur. J. Soil Sci., 10:235-244, 1959.

GIJSMAN, A.J. Soil aggregate stability and soil organic matter fractions under agropastoral systems established in native savanna. Aust. J. Soil Res., 34:891-907, 1996.

HAYNES, R.J. \& BEARE, M.H. Aggregation and organic matter storage in Mesothermal Humid soils. In: CARTER, M.R. \& STUART, B.A., eds. Structure and organic matter storage in agricultural soils. Boca Raton, Lewis Publishers, 1996. p.213-262.

HAYNES, R.J. \& BEARE, M.H. Influence of six crop species on aggregate stability and some labile organic matter fractions. Soil Biol. Biochem., 29:1647-1653, 1997.

HERNANI, L.C. \& GUIMARÃES, J.B.R. Efeitos de sistemas de preparo do solo e rotação de culturas em atributos físicos de um Latossolo Roxo. In: CONGRESSO LATINOAMERICANO DE LA CIENCIA DEL SUELO, 14., Temuco, 1999. Resúmenes. Temuco, Un. de La Frontera, 1999. CD-ROM.

KEMPER, W.D. \& CHEPIL, W.S. Size distribution of aggregation. In: BLACK, C.A., eds. Methods of soil analysis. Madison, American Society of Agronomy, 1965. p.499-510. (Agronomy, 9)
LIU, A.; MA, B.L. \& BOMKE, A.A. Effects of cover crops on soil aggregate stability, total organic carbon, and polysaccharides. Soil Sci. Soc. Am. J., 69:2041-2048, 2005.

MIELNICZUK, J.; BAYER, C.; VEZZANI, F.; LOVATO, T.; FERNANDES, F.F. \& DEBARBA, L. Manejo de solo e culturas e sua relação com estoques de carbono e nitrogênio do solo. In: CURI, N.; MARQUES, J.J.; GUILHERME, L.R.G.; LIMA, J.M.; LOPES, A.S.S. \& ALVAREZ V., V.H., eds. Tópicos em ciência do solo. Viçosa, MG, Sociedade Brasileira de Ciência do Solo, 2003. v.3. p.209-248.

OADES, J.M. Soil organic-matter and structural stability mechanisms and implications for management. Plant Soil, 76:319-337, 1984

PALADINI, F.L.S. \& MIELNICZUK, J. Distribuição do tamanho dos agregados de um solo Podzólico Vermelho-Escuro afetado por sistemas de culturas. R. Bras. Ci. Solo, 15:135$140,1991$.

PINHEIRO, E.F.M.; PEREIRA, M.G. \& ANJOS, L.H.C. Aggregate distribution and soil organic matter under different tillage systems for vegetable crops in a Red Latosol from Brazil. Soil Till. Res., 77:79-84, 2004.

REID, J.B. \& GOSS, M.J. Effect of living roots of different plant species on the aggregate stability of two arable soils. Eur. J. Soil Sci., 32:521- 542, 1981.

SALTON, J.C. Matéria orgânica e agregação do solo na rotação lavoura-pastagem em ambiente tropical, Porto Alegre, Universidade Federal do Rio Grande do Sul, 2005.158p. (Tese de Doutorado)

SALTON, J.C.; HERNANI, L.C.; FABRÍCIO, A.C. \& BROCH, D.L. Avaliação de atributos físicos e químicos do solo e rendimento de grãos na rotação lavoura-pastagem no sistema plantio direto. In: CONGRESO LATINOAMERICANO DE LA CIENCIA DEL SUELO, 14.,Temuco, 1999. Suelo - Ambiente - Vida: resúmenes. Temuco, Universidad de La Frontera, 1999. CD ROM.

SILVA, I. F. \& MIELNICZUK, J. Avaliação do estado de agregação do solo afetado pelo uso agrícola. R. Bras. Ci. Solo, 21:313-319, 1997b.

SILVA, I.F. \& MIELNICZUK, J. Ação do sistema radicular de planta na formação e estabilização de agregados do solo. R. Bras. Ci. Solo, 21:113-117, 1997a.

SILVA, M.L.N.; BLANCANEAUX, P.; CURI, N.; LIMA, J.M.; MARQUES, J.J.G.S.M. \& CARVALHO, A.M. Estabilidade e resistência de agregados de um Latossolo VermelhoEscuro cultivado com sucessão milho-adubo verde. Pesq. Agropec. Bras., 33:97-103, 1998.

SILVA, R.F.; AQUINO, A.M.; MERCANTE, F.M. \& GUIMARÃES,M.F. Populações de oligoquetos (Annelida: Oligochaeta) em um Latossolo Vermelho submetido a sistemas de uso do solo. Ci. Rural, 36:673-677, 2006.

SIX, J.; BOSSUYT, H.; DEGRYZE, S. \& DENEF, K. A history of research on the link between (micro) agregates, soil biota, and soil organic matter dynamics. Soil Till. Res., 79:7-31, 2004 
STEFAN, S. \& ZHANG, H. Earthworm casting: Stabilization or destabilization of soil structure? Soil Biol. Biochem., 29:469-475, 1997.

TISDALL, J.M. \& OADES, J.M. Organic matter and waterstable aggregates in soil. J. Soil Sci., 33:141-163, 1982.
VEZZANI, F.M. Qualidade do sistema solo na produção agrícola. Porto Alegre, Universidade Federal do Rio Grande do Sul, 2001. 184p. (Tese de Doutorado)

WRIGHT, A.L. \& FRANK, H.M. Tillage impacts on soil aggregation and carbon and nitrogen sequestration under wheat cropping sequences. Soil Till. Res., 84:67-75, 2005. 